\title{
Correspondence
}

\section{Positive suggestion during surgery reduces post bysterectomy emesis}

In some areas of anaesthetised brain Information may be registered, processed or both, ${ }^{1}$ leading to positive intraoperative suggestion to control post operative nausea and vomiting. However, these studies failed to establish a conclusive cause and effect relationship ${ }^{2,3}$ due to a lack of specificity of suggestions and standardisation for anaesthetic techniques/surgical procedures. We studied 50 ASA I or II patients, undergoing elective abdominal hysterectomy, for the effect of specific positive therapeutic suggestions on episodes of emesis. Patients were divided into two groups of 25 patients (Table). All patients received $4-5 \mathrm{mg} \cdot \mathrm{kg}^{-1}$ thiopentone for induction of anaesthesia and 0.1 $\mathrm{mg} \cdot \mathrm{kg}^{-1}$ vecuronium to facilitate intubation and relaxation. Anaesthesia was maintained with $0_{2}, \mathrm{~N}_{2} \mathrm{O}\left(\mathrm{FiO}_{2}\right.$ 0.35 ) and halothane $1-2 \%$. Positive suggestions (consisting of a male voice in the patients dialect) were played via head phones throughout anaesthesia to Group II patients only while a blank tape was played to Group I. Emetic episodes (vomiting and/or retching) were recorded in the recovery area and over the first 24 hours in the ward by a person blind to the groups. Patients with two or more emetic episodes were administered metoclopramide $0.25 \mathrm{mg} \cdot \mathrm{kg}^{-1} \mathrm{iv}$. Postoperative pain was relieved with diclofenac sodium $1 \mathrm{mg} \cdot \mathrm{kg}^{-1}$ im on demand. Data were analysed using " $\mathrm{Z}$ " rest.

None of the patients recalled the use of audiotape. Intraoperative suggestions reduced the incidence and severity of post-hysterectomy emetic episodes.

\section{REFERENCES}

1 Block RI, Ghoneim MM, Sumping ST, Ali MA. Human learning during general anaesthesia and surgery. $\mathrm{Br} \mathrm{J}$ Anaesth 1991; 66: 170-8.

2 Millar $K$. Efficacy of therapeutic suggestions presented during anaesthesia: re-analysis of conflicting results. $\mathrm{Br}$ J Anaesth 1993; 71: 597-601.
3 Lin WHD, Standen PJ, Aitkenbead AR. Therapeutic suggestions during general anaesthesia in patients undergoing hysterectomy. $\mathrm{Br} \mathrm{J}$ Anaesth 1992; 68: 277-81.

M. Maroof MD, S. Moied Ahmed MD, Rashid M. Khan MD, S. Bano MD, A.W. Haque MD Department of Anaesthesiology, King Fahad National Guard Hospital, Riyadh, Kingdom of Saudi Arabia.

\section{Output from a Drager Vapor 19.1 on a moving trolley}

We commonly transport anaesthetised children from an induction room to the operating room on a trolley equipped with an oxygen cylinder and a rigidly mounted Drager Vapor 19.1 halothane vaporizer. In order to determine whether or not this alters halothane delivery, we compared the output of two such vaporizers when stationary and in motion. Under similar circumstances a Fluotec vaporizer (model unspecified) has been reported to cause no clinically relevant variation in delivered halothane concentration. ${ }^{1}$

We collected gas into large plastic bags as our trolley was moved along a standardised route through our operating suite. An Ohmeda 5250 Respiratory Gas Monitor was used to measure the halothane concentrations. Twenty-eight pairs of vapour (stationary and in motion) from clinically relevant combinations of fresh gas flow and vaporizer dial settings were analysed from the first vaporizer. There was no clinically significant difference between the output during motion and the performance when stationary. However the output consistently measured $0.5 \%$ greater than the dial setting for 1,2 and $3 \%$ halothane at all flows. To confirm our findings, six further pairs of vapour were collected from a second vaporizer. The figure shows the mean and upper limit of measured halothane concentration.

Although we confirmed that our usual clinical practice does not change halothane delivery, an unexpect-

TABLE

\begin{tabular}{llll}
\hline Groups & Emetic incidents & Emetic episodes & Rescue antiemetic \\
\hline & $\mathrm{n} \& \%$ & $\mathrm{n}$ per pt. & $\mathrm{n} \& \%$ \\
I (No suggestion) $\mathrm{n}-25$ & $15(60 \%)^{*}$ & $3.1 \pm 1.2^{\star}$ & $10^{*}(66.6 \%) 10 / 15$ \\
II (Suggestion) $\mathrm{n}-25$ & $9(36 \%)$ & $1.7 \pm 0.6$ & $2(22.2 \%) 2 / 9$ \\
${ }^{*} P<0.05$ & & & \\
\hline
\end{tabular}


ed finding was that the enhanced output when using $100 \%$ oxygen was greater than the $15 \%$ increment described by the manufacturer. ${ }^{2}$

\section{REFERENCES}

1 Freidhoff $R J$, Abenstein JP. Safety of inhalation anesthetic delivery during patient transport. Anesthesiology 1991; 75: A893.

2 Operating Instructions Dräger-Vapor $(19 . n$, Drägerwerk Aktiengesellschaft, Federal Republic of Germany, 10th ed. 1987.

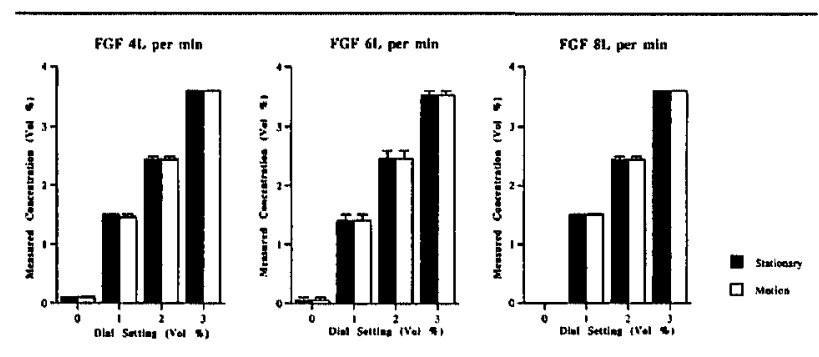

FIGURE Vaporizer output (mean, range) stationary and in motion, for FGF 4, 6, and $8 \mathrm{~L} \cdot \mathrm{min}^{-1}$.

AL Garden MB CHB FANZCA, CM Haberkern MD, ME Buckon MD, DV Baptiste BS RCP. University of Washington School of Medicine, Department of Anesthesiology, RN-10, Seattle, Washington, 98195 and Children's Hospital and Medical Center, 4800 Sand Point Way NE, Seattle, Washington, 98105, USA

\section{Alternative approach to airway management in Nager's syndrome}

We read Przybylo et al.'s report of retrograde intubation of a child with Nagers syndrome with interest, ${ }^{1}$ as we recently managed a similar child with an alternative technique. ${ }^{2}$

A two-year old, $12.5 \mathrm{~kg}$, uncooperative boy with Nager's syndrome ${ }^{3}$ presented for tracheostomy revision. Tracheostomy had been performed at birth but after its inadvertent removal one week previously, the child had increasing upper airway obstruction. Closure of the tracheostomy and inability to traverse the stoma fibreoptically was confirmed.

After premedication with midazolam $6 \mathrm{mg}$, and atropine $0.15 \mathrm{mg} i \mathrm{p}$, anaesthesia was induced with sevoflurane by mask and maintained with manual assistance and a size 2 oral airway before a size 2 LMA was easily inserted, followed by blind passage of a size 3.5 endotracheal tube through the LMA at first attempt. Tracheal placement was confirmed with auscultation, end-tidal $\mathrm{CO}_{2}$ and fibreoptic visualization.

Although rare, children with Nagers syndrome present considerable airway problems. We report our experience with a trans-LMA technique ${ }^{2}$ facilitating expeditious control of the airway (induction to intubation time of four minutes).

Evan G. Pivalizza MBCHB, FFASA

Becky L. McGraw-Wall MD, FACS*

Samia N. Khalil MD

Departments of Anesthesiology and Otolaryngology*

University of Texas Health Science Center at Houston

\section{REFERENCES}

1 Przybylo HJ, Stevenson GW, Vicari FA, Horn B, Hall $S C$. Retrograde fibreoptic intubation in a child with Nager's syndrome. Can J Anaesth 1996; 43: 697-9.

2 Rabb MF, Minkowitz HS, Hagberg CA. Blind intubation through the laryngeal mask airway for management of the difficult airway in infants. Anesthesiology 1996; 84: 1510-1.

3 Walker JS, Dorian RS, Marsh NJ. Anesthetic management of a child with Nager's syndrome (Letter). Anesth Analg 1994; 79: 1025-6.

\section{REPLY}

Pivalizza et al. report successful airway management of a child with Nager's syndrome using blind intubation via an LMA placed while the child was ventilating spontaneously. As stated in our original case report, ${ }^{1}$ there are several techniques that can be used for airway management in children that present with the potential combination of both difficult intubation and difficult mask pentilation. The critical point that we would reemphasize is that it is prudent to take advantage of the patient's natural airway and ability to breathe spontaneously when choosing which technique is best to secure the airway.

H.J. Przybylo MD, G.W. Stevenson MD, Steven C. Hall MD Department of Pediatric Anesthesia

Children's Memorial Hospital

Northwestern University Medical School

Chicago, IL 60614

\section{REFERENCE}

1 Przybylo HJ, Stevenson GW, Vicari FA, Horn B, Hall $S C$. Retrograde fibreoptic intubation in a child with Nager's syndrome. Can J Anaesth 1996; 43:697-9. 